\title{
Pathogenicity of Coagulase Negative Staphylococcus Chicken Isolates to 10 Days Old Broiler Chickens
}

\author{
Mariam Shokery H.M. ${ }^{1}$, M.A.Bosila², Wafaa A. Abd El-Ghany ${ }^{3}$, I.A.H. Redwan ${ }^{4}$ \\ and M.M. Amer ${ }^{3}$ \\ ${ }^{1}$ MVSc student, Poult. Dis. Dept., Faculty of Vet. Med., Cairo University.P.O. Code \\ 12211 Giza, Egypt, ${ }^{2}$ Dept of Poultry. Diseases, Vet. Res. Division, National Research \\ centre, P.O. Code 12311 Dokki, Giza, Egypt1, ${ }^{3}$ Poult.Dis. Dept., Facult.of Vet. Med., \\ Cairo University, P.O. Code 12211 Giza, Egypt, ${ }^{4}$ Bacteriol., Mycol. and Immunol. \\ Dept., Faculty of Vet. Med., Bani-suif University.P.O.Code 62511, Egypt.
}

\begin{abstract}
NE HUNDRED and sixty, 1-day old broiler chicks were grouped into 4 equal groups, at the $10^{\text {th }}$ day birds of groups $1-3$ were s.c inoculated with $0.5 \mathrm{ml}$ containing y $1.5 \times 10^{8}$ of S.xylosis, S. sciuri and S.lentus; respectively and group 4 was noninfected control.

Clinical signs in infected groups started at 2-3dpi as general signs. Signs disappear in Ciprofloxacillin treated subgroups $24 \mathrm{hr}$ post treatment and lasted to the $7^{\text {th }}$ day in non treated.

Average body weight gain in S.xylosis infected non treated was the highest (813.90 gm), followed by S. scuiri (778.50gm ) and 773.75 in S. lentus infected treated. FCR was the highest in control (1.69 treated and 1.74 non treated) followed by S. scuiri infected (1.81 non treated and 1.82 treated) and the lowest 1.94 was in S.lentus infected non treated. S. sciuri was reisolated from intestine and spleen $\left(5^{\text {th }} \mathrm{dpi}\right)$ and from intestine (7 and $\left.10 \mathrm{dpi}\right)$. While S.lentuswas reisolated from intestine, liver and spleen $\left(3^{\text {rd }} \mathrm{dpi}\right)$; from intestine and spleen $\left(5^{\text {th }}\right.$ dpi) and intestine $\left(10^{\text {th }} \mathrm{dpi}\right)$.
\end{abstract}

Histopathological lesion was recorded in infected group as hemorrhages with sinusoidal dilation, focal areas of vacuolar degeneration, fatty degeneration and shrinkage of hepatocytes in liver, necrotic changes of lymphocytes and vacuolion of corpuscle in spleen. Leucocytic infiltration, degeneration and necrosis of epithelium surface and intraepithelial as well as submucosal leucoytic infiltration were seen in intestine.

In conclusion the injected organisms induce mild subclinical disease with recording of histopathological lesions in liver, spleen and intestine. This area needs more investigation to explore pathogenicity of CoNS in chickens.

Keywords: Broilers, CoNS infection, FCR, Ciprofloxacillin, Histopathology

\section{Introduction}

Staphylococcosis is a systemic disease of birds caused by avian strains of Staphylococcus spp. $[1,2,3]$. The infection is common in poultry and game birds; especially in turkeys and broilers. Birds 4 to 6 weeks of age are extremely vulnerable; the most frequent sites of infections are bones, tendon sheaths, and leg joints [4]. Coagulasenegative staphylococci (CoNS) are mostly normal skin commensals and are much less pathogenic than S. aureus [5]. CoNS infections in chickens are considered to be opportunistic [6] and under the appropriate conditions became pathogenic. Research interest in CoNS has increased over the past decade due to their implication in infections in both humans and animals $[7,8]$.

CoNS was reported to be isolated from clinically infected chickens with cellulitis in broiler chickens [9] granulomas in the liver and lungs [10,11], gangrenous dermatitis, sub-dermal abscesses with the wing tips and the dorsal pelvic region $[12,13]$ S. xylosus and S. simulans were recovered from infected bone [14]. Infections with staphylococcus are usually characterized 
by increased heterophil counts and marked heterophilic infiltration of tendons, synovial membranes, and other affected organs [15].

Pathogenicity of $S$. aureus is due to toxic b-hemolysin and plasma coagulase [16]. Cunha Mde et al. [17] analyzed the CoNS virulence factors including hemolysins, lipase, lecithinase, DNAse, thermonuclease, and enterotoxin A, B or $\mathrm{C}$ in $37.6 \%$ of tested isolates . Zell et al. [18] demonstrate hemolytic activity and the exfoliative toxin A (ETA). Enterotoxins producing S. aureus is the most common cause of food-borne human illness throughout the world [19], the other CoNS species such as $S$. hyicus, S. sciuri, S. xylosus or S. cohnii are also important, particularly because of carriage the genes encoding antimicrobial resistance and enterotoxins genes [13,20,21].

The present study is an attempt to detect pathogenicity of CoNS chicken isolates to 10 days old broiler chickens.

\section{Material and Methods}

\section{Chickens}

One hundred and sixty , 1- day old broiler chicks were obtained as hatch from commercial hatchery. The used chicks was floor reared and fed on a balanced commercial ration.

\section{Ration}

The chicks were feed on ration according to the Ross broiler management manual and NRC [22] requirement for broiler. All housed chickens were given ration ad libitum.

\section{Bacterial strains}

CoNS strains $S$. xylosis, $S$. sciuri and $S$. lentus isolated and identified from broiler chicken flocks [23]. The isolates were separately on inoculated 5\% blood agar base and Mannitol salt agar (Difco) then incubated for $24-48$ hours at $37^{\circ} \mathrm{C}$. The resulted colonies were examined for identical morphological character of Staphylococcus species [24].

\section{Preparation of Bacterial Inoculums}

Used isolates were inoculated into Tryptic Soy Broth (TSB) and incubated at $37 \mathrm{C}^{\circ}$ for 24 hours. Infective dose of S.xylosis, S.sciuri and S.lentus was adjusted using colony forming units (cfu) was determined by plating tenfold dilutions on Tryptone soya agar as $0.5 \mathrm{ml}$ contains approxmitly $1.5 \times 10^{8}$ colony forming units $(\mathrm{CFU} / \mathrm{ml})$ [25].

\section{Reisolation of inoculated CoNS}

Cultures from liver, spleen and intestine of broiler chicks in tryptone soya broth then subcultures on mannitol salt agar finally Gram stained smears from these colonies were examined [24].

\section{Histopathological examination}

Tissue samples were collected from liver, spleen and intestine of all birds. These samples were fixed in neutral formalin $10 \%$ for $48 \mathrm{hrs}$ then underwent processing and staining according to Bancroft and Gamble [26]. After fixation, the sample were washed in running water, dehydrated in graduated ethyl alcohol, cleared in zylene and embedded and blocked in paraffin wax. Five microns tissue sections were mounted on clean glass slides and stained with hematoxyline and Eosin (H\&E stain).

\section{Experimental design}

At the $10^{\text {th }}$ day of age the used 160 chicks were divided into 4 equal groups (1- 4); 40 chicks each. Chicken of groups 1,2 and 3 were $S / C$ inoculated with $0.5 \mathrm{ml} 1.5 \times 10^{8}$ of S.xylosis, S. sciuri and S.lentus; respectively. Birds of group 4 were kept as noninfected control group. At the $15^{\text {th }}$ day with appearance of signs each group was divided into two equal sub groups. Supgroup a was treated with Ciprofloxacillin and subgroup b was kept as infected not treated. The treatment was done using Ciprofloxain (sensitive in vitro) in a dose of $1 \mathrm{~cm} /$ litre for 5 days .All groups were subjected to daily observation for clinical signs and mortalities with recording of average weekly BWG and FI for calculation of FCR[27]. Two birds/ group were randomly weighted and sacrificed at 3, 5, 7 and 10 days post infection (dpi) as well as 2 birds from control group for P.M with recordings of lesions and collection of intestine, spleen and liver samples in formol saline for histopathological examination.

\section{Results and Discussion}

To study pathogenicity of CoNS in broiler chicks at the $10^{\text {th }}$ day birds of groups 1,2 and 3); 45 chicks each; were $\mathrm{S} / \mathrm{C}$ inoculated with 0.5 $\mathrm{ml} 1.5 \times 10^{8}$ of S.xylosis, S. sciuri and S. lentus; respectively. Clinical signs in infected groups at 2-3dpi in the form of general signs of illness including depression, ruffled feather and off food. Group 3 infected with S.lentus showed additionally slight brownish diarrhea in 2 chicks. 
After 24 hours post treatment signs started to disappear in treated subgroups while nontreated ones restored their activity at the $10^{\text {th }}$ day (the $5^{\text {th }}$ post treatment ). This result can prove the possible efficacy of used drug as signed in disc sensitivity.

Performance of infected groups those consumed higher feed intake than noninfected control group (Table 1) while the control noninfected showing the lowest feed intake. Average body weight gain of infected non treated subgroups with S.xylosis (Gr 1b) was the highest
(813.90 gm), followed by (778.50gm ) in S. scuiri (Gr 2b) and 773.75 in the infected treated $S$. lentus Gr 3a). In the other hand treatment an infection not markedly affect body weight gain. FCR of control noninfected group was the highest 1.69 in treated and 1.74 in non treated while the lowest rate was in group $3 \mathrm{~b}$ (1.94) followed by 1.92 in groups $1 \mathrm{a}$ and $3 \mathrm{a}$. The result proved no marked effect of CoNS on performance [6]. Becker et al. [28] reported that CoNS have become a major nosocomial pathogen despite the normally sub acute and low inflammatory course of these infections in human .

TABLE 1. Average Feed intake/gm, Body weight gain and FCR of CoNS infected Ciprofloxacin treated and nontreated control chickens at $\mathbf{1 0}$ days post infection.

\begin{tabular}{|c|c|c|c|c|c|c|}
\hline Group & $\begin{array}{l}\text { Sub- } \\
\text { group }\end{array}$ & Infection & Treatment & Feed intake/gm & $\begin{array}{c}\text { Body weight } \\
\text { gain }\end{array}$ & FCR \\
\hline \multirow[t]{2}{*}{1} & $\mathbf{a}$ & \multirow{2}{*}{ S. xylosis } & + & 1434 & 748.40 & 1.92 \\
\hline & b & & - & 1506 & 813.90 & 1.85 \\
\hline \multirow{2}{*}{2} & $\mathbf{a}$ & \multirow{2}{*}{ S. sciuri } & + & 1330 & 732.05 & 1.82 \\
\hline & b & & - & 1405 & 778.50 & 1.81 \\
\hline \multirow{2}{*}{3} & $\mathbf{a}$ & \multirow{2}{*}{ S. lentus } & + & 1487 & 773.75 & 1.92 \\
\hline & b & & - & 1453 & 747.40 & 1.94 \\
\hline \multirow{2}{*}{4} & a & non infected & + & 1213 & 717.05 & 1.69 \\
\hline & $\mathbf{b}$ & control & - & 1190 & 685.25 & 1.74 \\
\hline
\end{tabular}

S. sciuri was reisolated from intestine and spleen of infected chickens at the $5^{\text {th }}$ dpi and from intestine at 7 and $10 \mathrm{dpi}$. While S.lentus was reisolated from intestine, liver and spleen at the $3^{\text {rd }}$ dpi and from intestine and spleen at the $5^{\text {th }}$ dpi as well as from intestine at the $10^{\text {th }} \mathrm{dpi}$ (Table 2). Cheville et al. [29] detected S. hyicus was isolated from birds in all stages of multiple outbreaks of acute severe fibrinopurulent lesions of the eyelids occurred in chickens and turkeys. Awan [30] studied pathogenicity of field isolates in 5-day-old embryonated eggs. S. intermedius or $S$. lentus demonstrated some pathogenicity in embryos while, these bacterial species caused neither clinical signs of acute or chronic nor mortality in 3-week-old broilers. Osman [31] stated that CNS was one of the main causes of avian cellulitis in chickens.

TABLE 2 . Reisolation of CoNS from infected chicken groups.

\begin{tabular}{|c|c|c|c|c|c|c|c|}
\hline Group & Infection & Subgroup & Treated & DPI & Intestine & $\begin{array}{c}\text { Organs } \\
\text { Liver }\end{array}$ & Spleen \\
\hline \multirow{3}{*}{1} & \multirow{3}{*}{ S.xylosis } & $\mathrm{b}$ & - & $3-10$ & 0 & 0 & 0 \\
\hline & & & & 5 & 1 & 0 & 0 \\
\hline & & $\mathrm{a}$ & + & 7 & 1 & 0 & 0 \\
\hline \multirow[t]{5}{*}{2} & \multirow[t]{6}{*}{ S. sciuri } & & & 10 & 1 & 0 & 0 \\
\hline & & & & $7-10$ & 0 & 0 & 0 \\
\hline & & & & 3 & 2 & 1 & 1 \\
\hline & & & & 5 & 0 & 2 & 1 \\
\hline & & a & + & 7 & 0 & 0 & 0 \\
\hline \multirow{2}{*}{3} & & & & 10 & 0 & 0 & 1 \\
\hline & S.lentus & & & 3 & 2 & 2 & 1 \\
\hline 4 & - & $\mathrm{b}$ & - & $3-10$ & 0 & 0 & 0 \\
\hline
\end{tabular}


The recorded histopathological lesion S.xylosis infected group 1b: Liver at $3^{\text {rd }}$ day dpi showing hemorrhages with sinusoidal dilation (Fig. 1), while focal areas of vacuolar degeneration in the form of fatty change and hydropic degeneration with moderate widening of hepatic sinusoids (Fig. 2 ) were recorded at $5^{\text {th }}$ and $7^{\text {th }}$ dpi. Spleen having mild to moderate necrotic changes of lymphocytes especially pyknosis and karyorrhexis (Fig. 3) at $3^{\text {rd }}$,

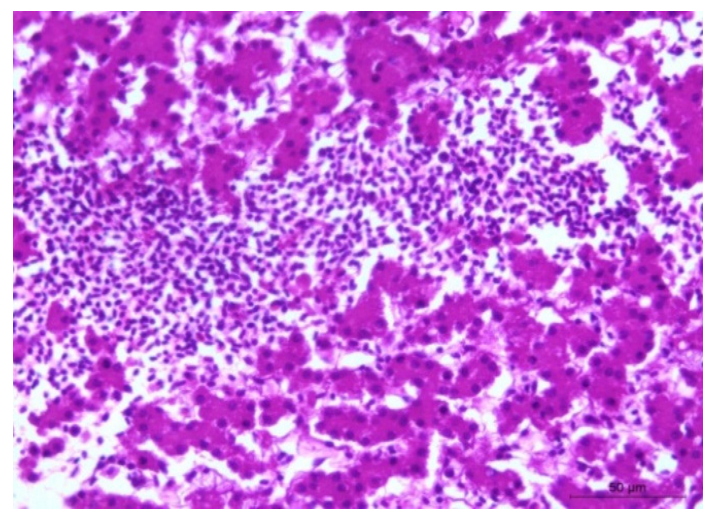

Fig. 1. LIver showing hemorrhages with sinusoidal dilation. (H \& E- stain). (X400).

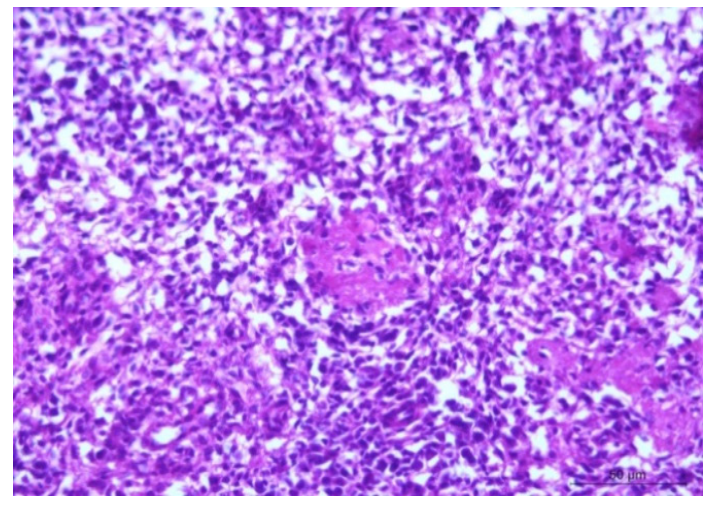

Fig. 3. Spleen having mild to moderate necrotic changes of lymphocytes. (H \& E-stain) (X400). $5^{\text {th }}$ and $7^{\text {th }}$ day dpi. Intestine at $3^{\text {rd }}$ day dpi showing moderate enteritis having diffuse leucocytic infiltration (mostly macrophages and lymphocytes) with degeneration and necrosis of intestinal mucosa and muscularis mucosa appeared wavy (Fig. 4) as well as focal submucosal mononuclear cell infiltration with mild degenerative changes intestinal epithelium and cystic dilation of a crypt (Fig. 5) at $5^{\text {th }}$ and $7^{\text {th }}$ dpi.

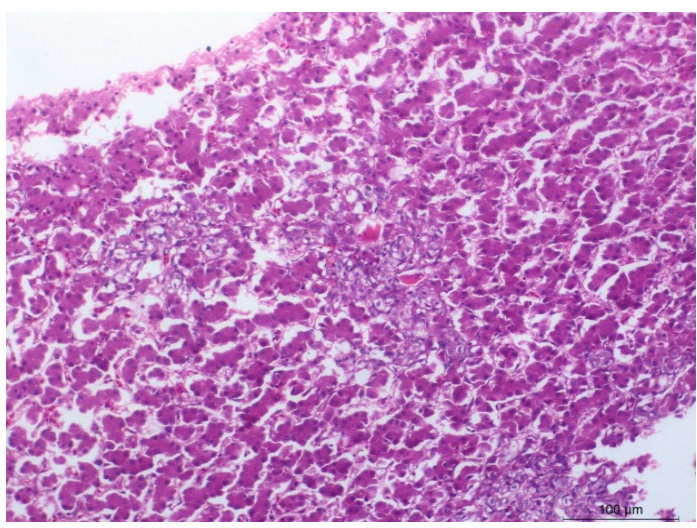

Fig. 2. Liver showing focal areas of vacuolar degeneration in the form of fatty change and hydropic degeneration with moderate widening of hepatic sinusoids. ( $\mathrm{H} \& \mathrm{E}$ stain) (x200).

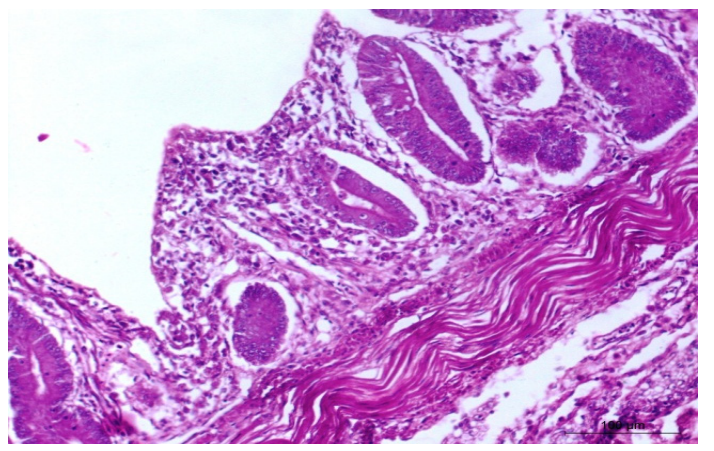

Fig. 4. intestine showing moderate enteritis with degeneration and necrosis of mucosa and muscularis mucosa appeared wavy. (H\&Estain) (X200).

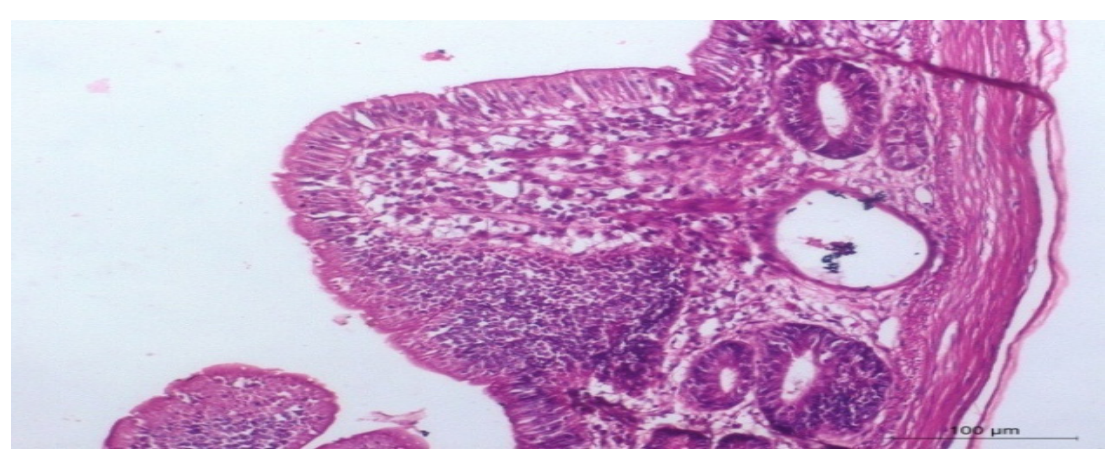

Fig . 5. intestine showing focal submucosal mononuclear cell infiltration with mild degenerative changes intestinal epithelium and cystic dilation of a crypt.

(H \& E- stain) (X200)

Egypt. J. Vet. Sci. Vol. 49, No.1 (2018) 
S. sciuri infected group 2b: Liver at $3^{\text {rd }}$ day dpi showing marked widening of hepatic sinusoids with moderate congestion (Fig. 6), at $5^{\text {th }}$ day dpi liver shows mild degeneration with perivascular leucocytic infiltration around central veins (Fig.7). Moreover, diffuse degenerative changes and congestion of blood vessels and hepatic

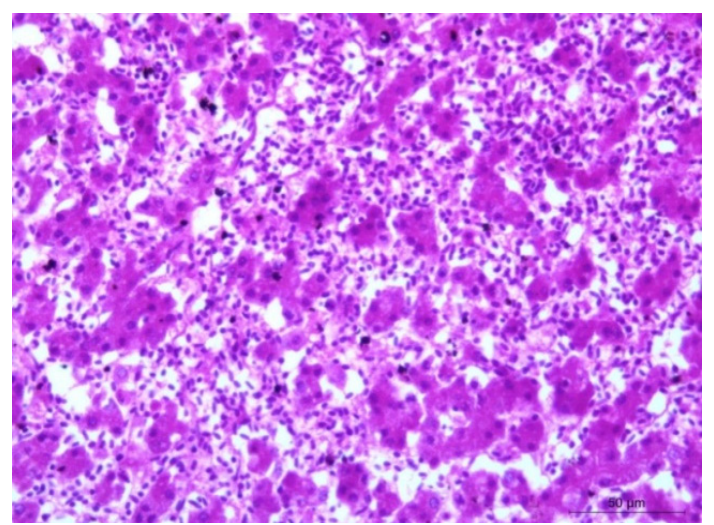

Fig. 6. liver showing marked widening of hepatic sinusoids with moderate congestion. (H \& E- stain) (X400).

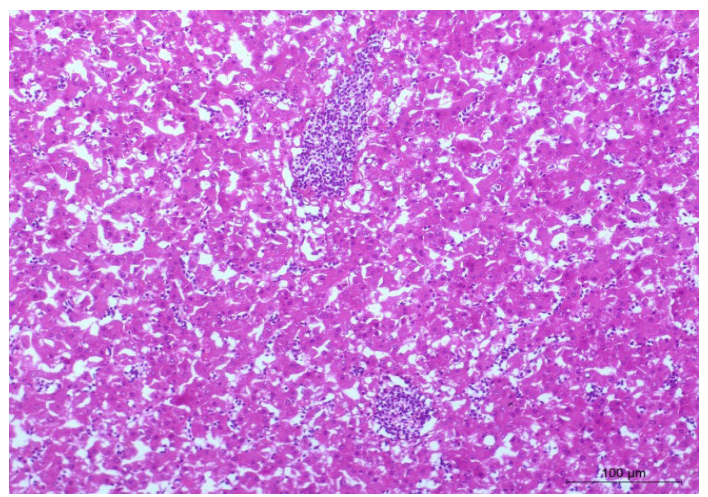

Fig. 8. Liver with diffuse degenerative changes and congestion of blood vessels and hepatic sinusoids (H \& E-stain) ( X200). sinusoids (Fig. 8) were seen at $7^{\text {th }}$ day dpi. Spleen at $5^{\text {th }}$ day dpi showing mild degree of vacuolion of splenic corpuscle (Fig. 9). Intestine at $7^{\text {th }}$ day dpi showing marked enteritis which characterized by severe degeneration and necrosis of intestinal mucosa and leucocytic infiltration (Fig. 10).

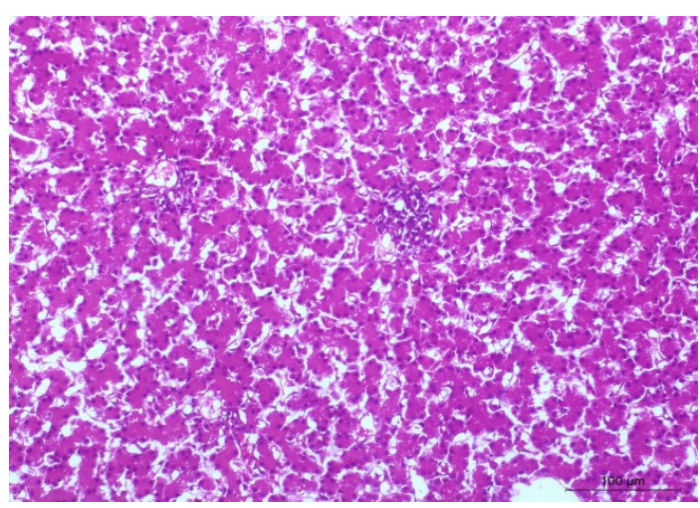

Fig.7. Liver show mild degeneration with perivascular leucocytic infiltration around central veins. (H \& E- stain) ( X200).

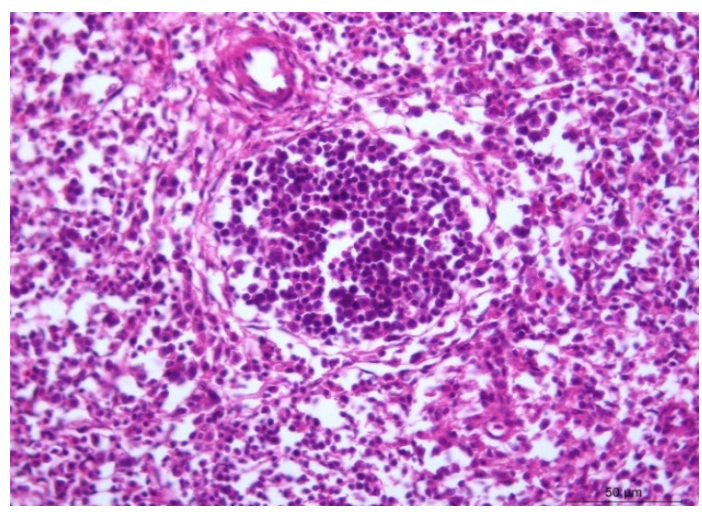

Fig. 9. Spleen showing mild degree of vacuolion of splenic corpuscle. (H \& E- stain). ( X400).

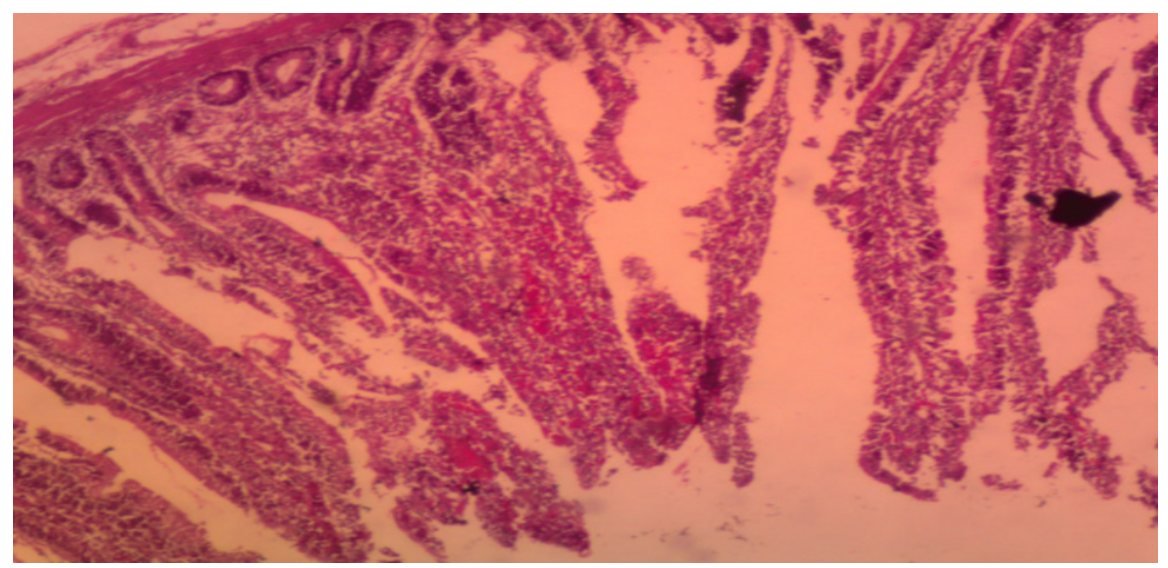

Fig. 10. Intestine showing marked enteritis which characterized by severe degeneration and necrosis of intestinal mucosa and leucocytic infiltration. (H \& E-stain) ( X200). 
S.lentus infected group 3b: Liver at $3^{\text {th }}$ dpi showing mild degree of vacuolar degeneration in the form of early fatty infiltration and hydropic degeneration (Fig. 11), at 5 and 7 days shrinkage of hepatocytes and marked widening of hepatic sinusoids with congestion (Fig. 12) and at $10^{\text {th }}$ dpi of gr $3 b$ showing small fat droplets within

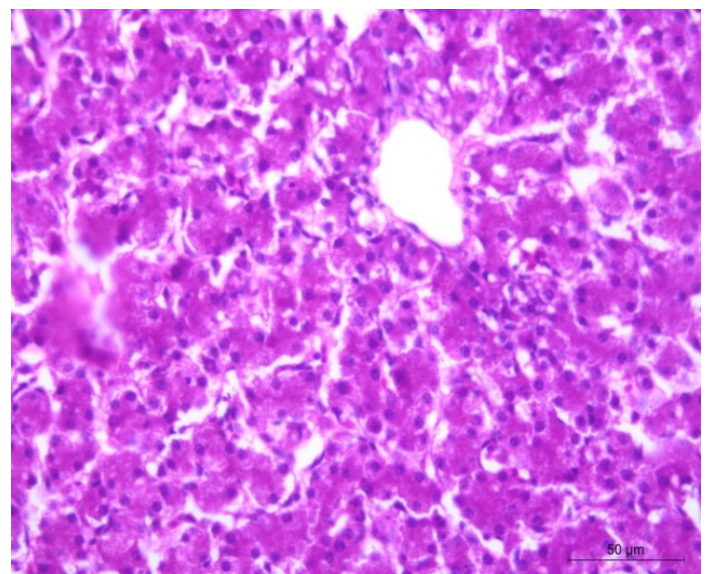

Fig. 11. Liver showing mild degree of vacuolar degeneration in the form of early fatty infiltration and hydropic degeneration. $(\mathrm{H}$ \& E-stain) (X400).

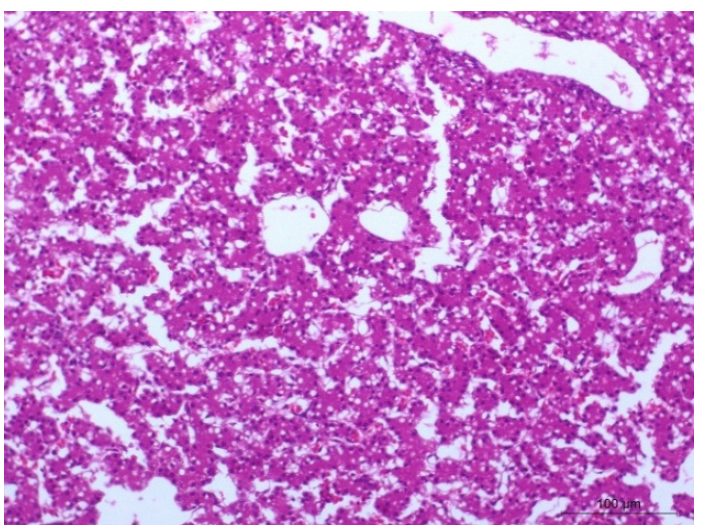

Fig. 13. Liver Showing small fat droplets within hepatocytes with very mild congestion of hepatic sinusoids (H \& E-stain) (X200).

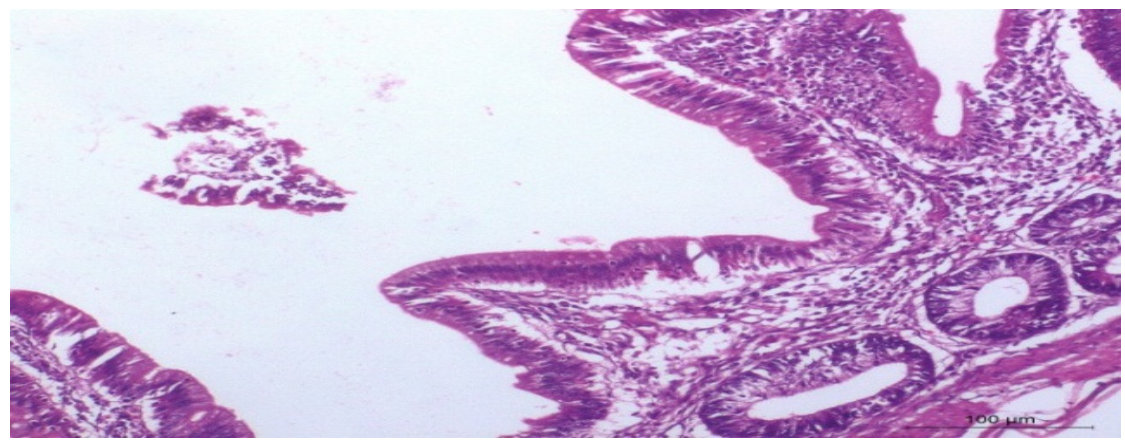

Fig. 15. Intestine of showing mild degeneration of surface epithelium with intraepithelial and submucosal leucoytic infiltration with.

(H \& E- stain) (X200). hepatocytes with widening and mild congestion of hepatic sinusoids (Fig. 13). Spleen $3^{\text {th }}$ dpi showing hyperplasia of lymphoid follicle (Fig.14), vacuolation and necrosis of splenic corpuscle (Fig 9 ) at $5^{\text {th }}$ day dpi. Intestine shows mild degeneration of surface epithelium with intraepithelial and submucosal leucoytic infiltration (Fig. 15).

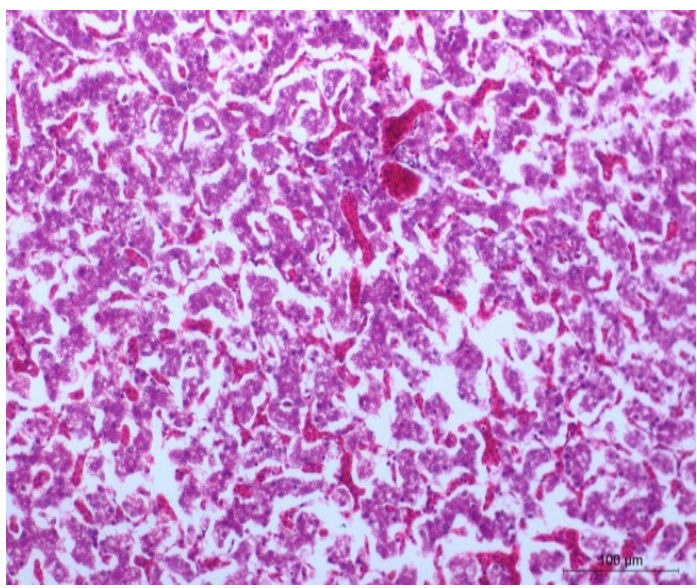

Fig. 12. liver Showing shrinkage of hepatocytes and marked widening of hepatic sinusoids with congestion (H \& E-stain) (X200).

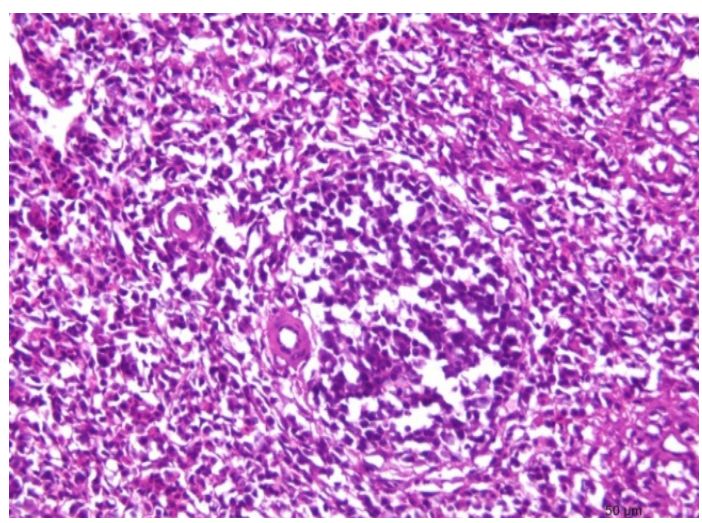

Fig. 14. Spleen showing hyperplasia of lymphoid follicle. (H \& E- stain) (X400).

Egypt. J. Vet. Sci. Vol. 49, No.1 (2018) 
S.lentus infected treated gr 3a: Liver at 5dpi showing small fat droplets within hepatocytes with very mild congestion of hepatic sinusoids (Fig. 13) Spleen S.lentus infected treated at $5^{\text {th }}$ day dpi showing hyperplasia of lymphoid follicle (Fig. 14).

Stępień-Pyśniak et al. [32] reported that heart revealed multifocal conglomerates of bacterial colonies attached to the valvular endocardium, threads of fibrin, and inflammatory cells with the presence of heterophils. The detection of histological change in infected nontreated groups can support the statement CoNS are shown to have role as opportunistic pathogens [33]. Tsai et al. [34] and Stępień-Pyśniak et al. [32] suggested a strong association between CoNS and endocarditis in broiler chickens. This lesions can be due to action of virulence factors including slime-producing $[35,36,37,38]$, toxic shock syndrome toxin 1 (TSST-1) [18,39], enterotoxin $[18,39]$ and biofilms formation $[40]$.

As Pathogenicity of S.aureus is due to toxic b-hemolysin and plasma coagulase [4]. Cunha Mde et al. [17] analyzed the CoNS virulence factors including hemolysins, lipase, lecithinase, DNAse, thermonuclease, and enterotoxin A, B or C in $37.6 \%$ of tested isolates . Zell et al. [18] demonstrate hemolytic activity and the exfoliative toxin A (ETA) .Shimaa El-Nagar et al. [21] stated that enterotoxins genes in CoNS sec and see were found in 6 isolates with $10.3 \%$ for each. Valle et al. [41] found a toxigenic capacity in 45 (16.5\%) CoNS isolates, including S. xylosus.

In conclusion, from results of this study used organisms can induce subclinical disease while, histopathological lesions in liver, spleen and intestine of infected chickens were recorded. This area needs more investigation to explore factors potentiate pathogenicity of CoNS in infected chickens.

\section{References}

1. Skeeles, J.K., Staphylococcosis. In: Diseases Antibiotic of Poultry, 9 edition. B.W.Calnek, H.J. Barnes, C.W. Beard, W.M. Reid and H.W. Yoder. Iowa State University Press, Ames, IA, pp: 293-299 (1991)

2. Devriese, L. A. Pathogenic staphylococci in poultry. World's Poult. Sci. J., 36, 227-236. (1980).

3. Pepe, O., Blaiotta, G., Bucci, F., Anastasio, M., Aponte, M. and Villani, F., Staphylococcus aurous taphylococcal enterotoxin A in breaded chicken and products: detection and behavior during the cooking process. Applied Environmental Microbiology 72, 7057-7070 (2006).

4. Jordan, F.T.W., Staphylococci. In: Jordan, F.T.W., Pattison, M. (Eds.), poultry Diseases, 4th Edition. Saunders, London, pp.66-69 (1996).

5. Livermore, D.M. Antibiotic resistance in staphylococci. Internat. J. of Antimicrobial Agents, 16, 3-10(2000).

6. Scanlan, C. M. and Hargis B. M.. A bacteriologic study of scabby-hip lesions from broiler chickens in Texas. J. Vet. Diagn. Invest. 1,170-173(1989).

7. Boerlin, P., Kuhnert, P., Hüssy, D. and Schaellibaum, M. Methods for identification of Staphylococcus aureus isolates in cases of bovine mastitis. Journal of Clinical Microbiology, 41(2), 767-771(2003).

8. Koksal, F., Yasar, H. and Samasti, M. Antibiotic resistance patterns of coagulase-negative staphylococcus strains isolated from blood cultures of septicemic patients in Turkey. Microbiological Research, 164 (4), 404-410(2009).

9. Norton, R.A, Bilgili, S.F. and Mcmurtrey. B.C. A reproducible model for the induction of avian cellulitis in broiler chickens. Avian dis. 41, 422-428 (1997).

10. Munger, L. L. and Kelly, B. L. Staphylococcal granulomas in a leghorn hen. Avian Disease, 17 858-860 (1973).

11. Linares, J. A. and Wigle, W. L. Staphylococcus aureus pneumonia in turkey poults with gross lesions resembling Aspergillosis. Avian Disease 45,1068-1072 (2001).

12. Sleekes J.K. Staphylococcosis. In: Diseases of Poultry. 10th edition (BW Calnek editor). Iowa State University Press, Ames. pp.: 247- 253 (1997).

13. Aarestrup, F.M., Agers, L.Y., Ahrens, P., Lrgensen, J.C., Madsen, M. and Jensen, L.B. Antimicrobial susceptibility and presence of resistance genes in staphylococci from poultry. Vet. Microbiol., 74(4), 353-64 (2000).

14. McNamee P.T. and Smyth J.A. Bacterial chondronecrosis with osteomyelitis ('femoral head necrosis') of broilers chickens : a review. Avian Pathol., 29, 253-270 (2000).

15. Andreasen C.B., Latimer K.S., Harmon B.G., Glisson J.R., Golden J.M. and Brown J. Heterophil function in healthy chickens and in chickens with experimentally induced staphylococca tenosynovitis. Vet. Pathol., 28, 419-427(1991).

16. Jensen, M. W., Downs W. C., Morrey J. D., Nicoll T. R., LeFevre S. D., and Meyers, C. M. 
Staphylococcosis of turkeys. 1. Portal of entry and tissue colonization. Avian Dis., 31, 64-69(1987).

17. Cunha MdeL ,Rugolo L.M. and Lopes C.A. Study of virulence factors in coagulase-negative staphylococci isolated from newborns. MemInst Oswaldo Cruz.. 101 (6), 661-668 (2006).

18. Zell C., Resch M., Rosenstein R., Albrecht T., Hertel C. and Götz F. Characterization of toxin production of coagulase-negative staphylococci isolated from food and starter cultures. Int. J. Food Microbiol., 127 (3), 246-251(2008).

19. Do Carmo, L.S., Cummings, C., Linardi, V.R., Dias, R.S., De Suoza, J.M., De Sena, M.J., Dos Santos, D.A., Shupp, J.W., Pereira, R.K. and Jett, M. A case study of massive staphylococcal food poisoning incident. Food borne Pathogens and Dis., 1, 241246 (2004).

20. Chah, K. F., Gómez-Sanz, E., Nwanta, J. A., Asadu, B., Agbo, I. C., Lozano, C., and Torres, C. Methicillin-resistant coagulase-negative staphylococci from healthy dogs in Nsukka, Nigeria. Brazilian J. Microbiol., 45 (1), 215-220 (2014).

21. Shimaa El-Nagar, Abd El-Azeem M.W., Nasef A.S. and Sultan S. Prevalence of Toxigenic and Methicillin Resistant Staphylococci in Poultry Chain Production . J. Advanced Vet. Res., 7 (2) 33 38 (2017)

22. NRC. National Research Council. National requirement for poultry. $9^{\text {th }}$ ed., Washington $\mathrm{DC}$, National Academy Press. (1984)

23. Mariam-Shokery H. M., RedwanI. A. H., Wafaa A. Abd El-Ghany and Amer M. M.. Molecular detection of antibiotic resistance genes in identified Coagulase Negative Staphylococci from chickens flocks and hatcheries in Egypt. In Press. (2018)

24. Quiun P.J., Markey B.K., Carter M.E., Donnelly W.J. and Leonard F.C. Veterinary microbiology and microbial diseases. USA: Blackwell Publ. Co., p.23-26. (2002).

25. Sieuwerts S., de Bok A. M. F., Mols E. , De Vos M. W., Vlieg van H. J. A simple and fast method for determining colony forming units. Letters in Applied Microbiol., 47, 275-278 (2008).

26. Bancroft J.D. and Gamble M.. Theory and Practice of Histological Techniques. $6^{\text {th }}$ ed., Churchill Livingstone, Elsevier, China.(2008).

27. Okumuş, İ. and Mazlum, M.D. Evaluation of commercial trout feeds: feed consumption, growth, feed conversion, carcass composition and bioeconomic analysis. Turkish J. of Fisheries and Aquatic Sciences, 2 (2), 101-107 (2002).
28. Becker, K., Heilmann, C., and Peters, G. Coagulasenegative staphylococci. Clin. Microbiol. Rev., 27, 870-926. doi: 10.1128/CMR.00109-13(2014).

29. Cheville, N. F., Tappe, J., Ackermann, M., and Jensen, A. Acute fibrinopurulent blepharitis and conjunctivitis associated with Staphylococcus hyicus, Escherichia coli, and Streptococcus sp. in chickens and turkeys. Vet. Pathol., 25 (5), 369 375(1988).

30. Awan A.M. Systemic Bacterial Infections in Broiler Chickens. Thesis for Master of Science in Veterinary Science. Oregon State University (1997)

31. Osman, J. Bacteria Associated With Avian Cellulitis In Broiler Chickens. M.Sc Thesis, Microbiology, Faculty of Vet. Med. University of Khartoum (2002).

32. Stępień-Pyśniak, D., Wilczyński, J., Marek, A., Śmiech, A., Kosikowska, U., and Hauschild, T. Staphylococcus simulans associated with endocarditis in broiler chickens. Avian Pathol., 46 (1), 44-51(2017).

33. Mack D., Rohde H., Harris L.G., Davies A.P., Horstkotte M.A. and Knobloch J.K. Biofilm formation in medical device-related infection. Int $J$ Artif Organs., 29, 343-359 (2006).

34. Tsai, S. S., Chen, L. J., Shih, C. Y., Chang, T. C., Chiou, M. T., and Chuang, K. P. Joint lesion in taiwan native colored broiler chicken with natural and experimental Staphylococcus aureua or S.cohnii. Taiwan Vet. J., 41 (04), 237-244 (2015).

35.Ishak M.A., Gröschel D.H., Mandell G.L., Wenzel R.P. Association of slime with pathogenicity of coagulase-negative staphylococci causing nosocomial septicemia. J. Clin. Microbiol., 22 (6), 1025-1029 (1985).

36. Végh Z. and Gacs M. Correlation of slime production and pathogenicity of coagulasenegative staphylococci. Orv. Hetil., 4, 131 (5), 231234 (1990).

37. Kübler J. Extracellular polysaccharides of coagulase-negative staphylococci and their role in pathogenicity. Postepy Hig Med Dosw., 52 (4), 311 323 (1998).

38. McNamee, P.T., McCullagh, J.J., Throp, B.H., Ball, H.J., Graham, D.G., McCullough, S.J.,McConaghy, D. and Smyth, J.A. Study of leg weakness in two commercial broiler flocks. Vet. Rec., 143, 131-135 (1998).

39. Crass B.A. and Bergdoll M.S. Involvement of coagulase-negative staphylococci in toxic shock syndrome. J Clin Microbiol., 23 (1), 43-45(1986). 
40. Otto M. Virulence factors of the coagulasenegative staphylococci. Front Biosci., 9, 841-863(2004).

41. Valle, J., Vadillo, S., Piriz, S. and Gomez-Lucia, E. Toxic Shock Syndrome Toxin 1 (TSST-1) production by staphylococci isolated from goats and presence of specific antibodies to TSST-1 in serum and milk. Appl. Environ. Microbiol.57, 889891(1991).

(Received 22/03/2017;

accepted 03/05/2018)

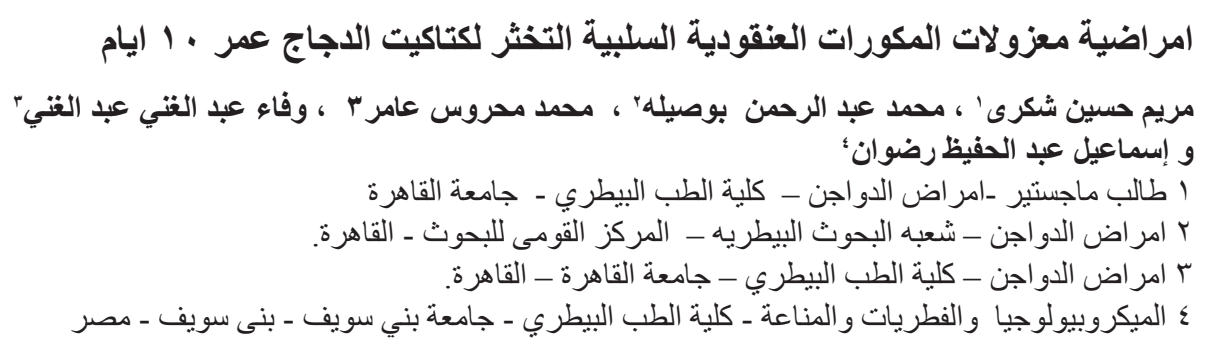

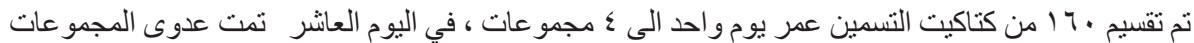

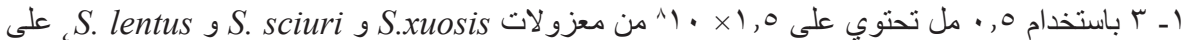

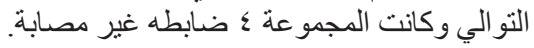

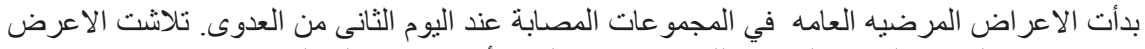

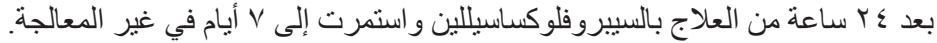

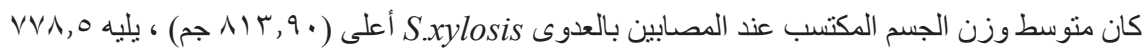

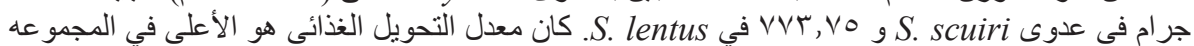

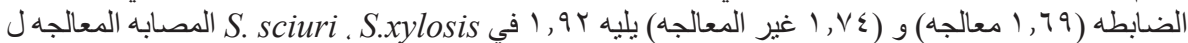

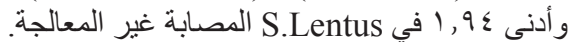

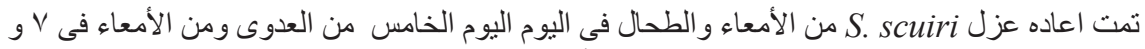

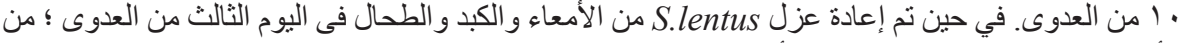
الأمعاء و الطحال (0 من العدوى) و والأمعاء فئ في اليوم العانشر.

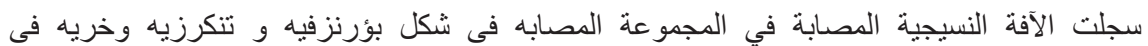

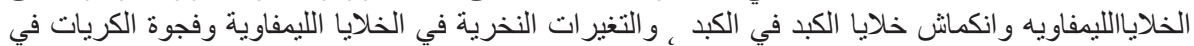

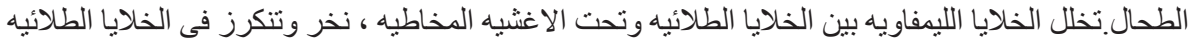
المبطنه للامعاء.

في الختام تم التعرف على عدوى تحت اكلينكيه جر اء عدوى الكتاكيت بعتر ات المكور العنقودى سالبه التخثر

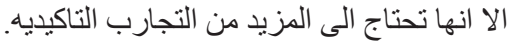

